\title{
Andrés Bello y la tradición clásica. Algunos problemas para su valoración
}

\author{
Mariano Nava Contreras ${ }^{1}$
}

Recibido: 12 de Julio de 2019 / Aceptado: 4 de Septiembre de 2019

Resumen. Andrés Bello es tal vez el mayor humanista de la América hispánica. Poeta, filólogo, lingüista, educador, filósofo, jurista, legislador, político y periodista, su vasta obra descansa en una sólida formación clásica que se hace evidente en todas y cada una de sus facetas. Formado durante los años finales del escolasticismo colonial en la Caracas donde nació en 1781, completó y profundizó su educación en Londres durante las primeras décadas del siglo XIX y desarrolló la mayor parte de su obra en Santiago de Chile, donde murió en 1865. Su ciclo vital alcanza, pues, casi un siglo, durante el que se verificaron importantes cambios en la evolución de los estudios clásicos y del pensamiento europeo en general. Esta aproximación intenta identificar algunos de los problemas que han impedido hacer una correcta valoración del lugar esencial que ocupa la tradición clásica en la obra de Andrés Bello.

Palabras clave: Andrés Bello; Tradición Clásica; Humanismo hispanoamericano; Venezuela; Chile.

\section{[en] Andrés Bello and the Classical Tradition. Some Problems for its Assessment}

\begin{abstract}
Andrés Bello is perhaps the greatest humanist of Hispanic America. Poet, philologist, linguist, educator, philosopher, jurist, legislator, politician and journalist, his vast work rests on a solid classical formation that is evident in each and every one of its facets. Formed during the final years of colonial scholasticism in Caracas, where he was born in 1781, he completed and deepened his education in London during the first decades of the nineteenth century and developed most of his work in Santiago de Chile, where he died in 1865 . His life cycle thus reaches almost a century, during which important changes were observed in the evolution of classical studies and of European thought in general. This approach attempts to identify some of the problems that have prevented us from correctly assessing the essential place occupied by the classical tradition in the work of Andrés Bello.
\end{abstract}

Keywords: Andrés Bello; Classical Tradition; Hispanic American Humanism; Venezuela; Chile.

Sumario. 1. Leer un tiempo. 2. Leer un lugar. 3. Leer una obra. 4. Conclusiones

Cómo citar: Nava Contreras, M. (2020) Andrés Bello y la tradición clásica. Algunos problemas para su valoración, en Cuadernos de Filología Clásica. Estudios griegos e indoeuropeos 30, 253-266.

1 Universidad de Los Andes, Mérida, Venezuela, Departamento de Lenguas y Literaturas Clásicas mnava@ula.ve 
El estudio de las clásicas es el estudio de lo que ocurre entre la Antigüedad y nosotros mismos. No solo es el diálogo que mantenemos con la cultura del mundo clásico; también es el diálogo que entablamos con aquellos que antes que nosotros dialogaron con el mundo clásico.

Mary Beard, La herencia viva de los clásicos

Hubo una época "feliz" en que los estudios de "tradición clásica" se limitaban a contabilizar, generalmente en tono encomiástico, las referencias a la mitología, la historia o la literatura antiguas presentes en la obra de determinado autor, para llegar a la conclusión de que se trataba de una persona "muy culta". Las razones de estas referencias generalmente eran explicadas de manera sencilla, a partir de los movimientos o modas literarias en las que nuestro autor era clasificado, y hasta ahí. Hoy sabemos que las cosas no son tan sencillas. Hoy sabemos que la presencia, apropiación y reelaboración de los elementos de la cultura clásica en la obra de un autor, no solamente moderno, obedece a una complejidad de factores que implican muchos tipos de lecturas. El caso de Andrés Bello es una muestra patente.

\section{Leer un tiempo}

La tarde del primero de agosto de 1770 dos profesores de filosofía de la Real y Pontificia Universidad de Caracas, el Conde de San Javier y Antonio Suárez Valverde, conversaban plácidamente. Cuentan los historiadores que en algún momento de la conversación Valverde dejó caer alguna frase irónica sobre "la inutilidad de los estudios aristotélicos" y el Conde, compresiblemente, "montó en cólera". De inmediato exigió a Valverde que se retractara de lo dicho, o de lo contrario pusiera sus impertinentes ofensas por escrito. Valverde accedió encantado y escribió dos tesis temerarias que publicó y circularon por Caracas una semana después en hojas sueltas: 1) "Que la filosofía de Aristóteles ni para tratar la Sagrada Escritura es útil sino perniciosa", y 2) "Que Santo Tomás floreció en los siglos de ignorancia".

Esas hojas fueron recogidas por Francisco de Miranda, quien las conservó en sus famosos archivos ${ }^{2}$. ¿Pero quién era este Valverde que se atrevía a afirmar semejantes infamias? ¿Cómo osaba ofender nada menos que a la autoridad del más grande de los filósofos? ¿Cómo se atrevía a contender con uno de los profesores de más rancio abolengo de la universidad? Antonio Suárez Valverde ("el tal Valverde" del que nos habla Parra León sin ocultar su desdén) era un sacerdote y filósofo que había estudiado Teología y Derecho Civil en la Universidad de Santo Tomás, en Santo Domingo, donde había dado clases por algún tiempo. Allí al parecer tuvo su primer contacto con la llamada "filosofía moderna", los libros franceses e ingleses que estaban revolucionando el pensamiento y la ciencia en Europa. Nada que no se supiera también en Caracas como en otras ciudades de Hispanoamérica, donde -lo sabemos- los "libros prohibidos" eran leídos de manera más o menos clandestina por lo menos desde mediados del siglo XVIII (Henríquez Ureña 1994: 39). La diferencia era que, al parecer, Valverde era de temperamento vehemente y tenía mal carácter, y no había sido capaz de disimular su desprecio por las viejas ideas.

2 Disponible: http://www.franciscodemiranda.org/colombeia/. Cf. asimismo Parra León (1989: 46-53) y Leal (1981: 60). 
Sostenía que el pensamiento de Aristóteles era una "servil sentina de errores" y negaba que Santo Tomás hubiera aprendido algo de los "infames" libros del filósofo de Estagira.

Para que nos hagamos una idea de la osadía de Valverde, tenemos que hablar de cómo era la universidad caraqueña en tiempos de la colonia. Según Ildefonso Leal y otros historiadores, la Universidad de Caracas, como las demás en la América colonial, era extremadamente dogmática y conservadora (Leal 1981: 60). En sus aulas y pasillos solo se podía hablar latín; los alumnos, antes de comenzar las clases de filosofía, debían hacer la oración que hacía Santo Tomás en el siglo XII (por supuesto, también en latín), en que pedía al Altísimo que le abriera el entendimiento, y los catedráticos debían jurar que defenderían el dogma de la Inmaculada Concepción (Tejera 1996: 359-379). En estas aulas se enseñaba teología y filosofía medieval (Nava Contreras 1997: 179-182), siempre según los libros de Aristóteles, llamado por antonomasia "El Filósofo" (Nava Contreras 2016: 82-132), y los de Tomás de Aquino, el "Angélico Doctor", el más ilustre de sus sucesores, que en la Edad Media había logrado conciliar la doctrina cristiana con el pensamiento de los griegos. Ambos eran las máximas autoridades de la universidad, incontestables, sagradas, intocables.

Contra este par nada menos descarga su artillería el profesor Valverde. Había llegado a Caracas al parecer aceptando un alto cargo eclesiástico y aquí se había vinculado a la vieja universidad. De aquí partió también al poco tiempo, después de haber protagonizado la primera controversia filosófica suscitada en una universidad venezolana, y tal vez no resulte tan arriesgado conjeturar que a causa de ella. Sin embargo, a pesar de lo virulento de la polémica, hay que notar con Parra León que, "ni Valverde fue perseguido, ni salió la Universidad en defensa del Conde de San Javier, que era de los más influyentes de su claustro" (Parra León 1989: 52). Esto lleva a pensar que pudiera estar comenzando a propagarse un clima de tolerancia y una inclinación a las reformas (tan propias de estos años borbónicos) y a las nuevas ideas en las aulas venezolanas e hispanoamericanas de aquellos tiempos. Como nota Parra León, no pensemos, ni de lejos, que la violenta diatriba entre Valverde y San Javier por culpa de Aristóteles "fue cosa ocasional y pasajera". Antes bien, el hecho revela un desafío a la autoridad y a la tradición establecida que presagia los dramáticos cambios que pronto sufrirá la mentalidad de los venezolanos. Cambios que conducirían a la independencia en solo cuatro décadas. Estos cambios son percibidos con fino olfato por el barón de Humboldt, quien comenta de su visita a la pequeña capital en diciembre de 1799: "En Caracas existen, como donde quiera que se prepara un gran cambio en las ideas, dos categorías de hombres, pudiéramos decir, dos generaciones muy diversas" (1985: tomo 2, 331).

Esta es también la ciudad donde se forma Andrés Bello ${ }^{3}$. Siendo muy joven frecuentó el Convento de los Mercedarios, donde aprendió latín con el fraile Cristóbal de Quesada. Cuentan los biógrafos de Bello que la muerte del maestro en 1796 interrumpió la traducción del libro $\mathrm{V}$ de la Eneida que ambos llevaban adelantada ${ }^{4}$.

\footnotetext{
Para una valoración del estado social, económico y político de la ciudad de Caracas a finales del s. XVIII y comienzos del XIX, $c f$. el clásico trabajo de M. McKinley (1987). Acerca de la "leyenda negra" que pretende que la Caracas colonial era un lugar de atraso y oscurantismo, Miguel Ángel Campos nota que "nunca fue Caracas el lugar de oscurantismo y pocas letras que promocionó el discurso antiespañol -y por razones comprensibles - creado por la generación que debía negar la Colonia, desde Baralt hasta Juan Vicente González”. Y más adelante: "Será un autor colombiano, Miguel Antonio Caro, quien se da cuenta en el último tercio del siglo XIX del equívoco sobre la vida intelectual de la Caracas colonial, justamente en su estudio sobre Bello, Andrés Bello, estudio biográfico y crítico, Bogotá, 1881" (Campos 2017: 11-27).

$4 \quad$ Las biografías más importantes de Andrés Bello son la de Pedro Miguel Amunátegui (Vida de don Andrés Bello, Santiago de Chile 1882), quien conoció al maestro y tuvo acceso directo a sus manuscritos; Rafael Caldera (Andrés Bello,
} 
Pronto los talentos del joven Andrés ganarán reputación entre los círculos ilustrados de la pequeña capital de la Provincia de Venezuela. En realidad, no hubo prueba o concurso promovido por la vieja universidad en que no venciera. Ese mismo año de 1796, con quince años de edad, gana el concurso de traducción latina. En 1799 gana el primer premio del concurso de filosofía natural, y el 9 de mayo del año siguiente no tendrá problema en presentar simultáneamente las cinco asignaturas necesarias para obtener el Bachillerato en Artes con las mayores calificaciones. También cursó estudios de derecho y medicina, que dejó inconclusos.

Habitué de ágapes y tertulias, resultaba rara aquella en la que "el cisne del Anauco" no deleitase a lo más granado del mantuanaje con alguna de sus exquisitas declamaciones. Sus composiciones conservadas de entonces ya muestran ese inédito maridaje entre el motivo clásico y la exuberancia del paisaje del trópico americano que es sello de su poesía ${ }^{5}$. Es el caso del soneto Mis deseos (ca. 1800), de inocultable ascendencia horaciana patente en su epitafio, hoc erat in votis ${ }^{6}$, en el que estudiosos como Lubio Cardozo (1981: 29 ss.) han identificado indudables resonancias del motivo del beatus ille ${ }^{7}$ :

¿Sabes, rubia, qué gracia solicito cuando de ofrendas cubro los altares?

No ricos muebles, no soberbios lares,

Ni una mesa que adule el apetito.

De Aragua a las orillas un distrito que me tribute fáciles manjares, do vecino de mis rústicos hogares entre peñascos corra un arroyito.

Para acogerme en el calor estivo, que tenga una arboleda también quiero do crezca junto al sauce el coco altivo.

¡Felice yo si en este albergue muero; $\mathrm{y}$ al exhalar mi aliento fugitivo, sello en tus labios el adiós postrero! ${ }^{8}$

Caracas 1935), quien más bien se planteó hacer una valoración general de su obra, así como una breve y más reciente a cargo de Pedro Cunill Grau (Andrés Bello, Caracas 2006). Sin embargo, el estudio más profundo y completo acerca de la vida y obra del sabio venezolano hasta el momento se debe a Iván Jaksic (Andrés Bello. Pasión por el orden, Santiago de Chile 2001, y Caracas 2007, que es traducción de su Andrés Bello. Scholarship and Nation-building in Nineteenth Century Latin-América, Cambridge 2001). El estudio de Jaksic tiene el doble mérito de entender la obra del sabio venezolano bajo su circunstancia histórica (el fin del imperio español en América y el surgimiento del orden republicano postcolonial), así como bajo los avatares de su intensa vida personal. En esta investigación seguimos los datos aportados por esta biografía. Mérito tiene también la especie de biografía intelectual de Emir Rodríguez Monegal, El otro Andrés Bello (Caracas 1969). Finalmente, resulta interesante el trabajo de Jorge Bocaz, Andrés Bello. Una biografia cultural (Bogotá 2000), por los aportes a la iconografía bellista que contiene.

5 Acerca de la producción poética de la época caraqueña de Bello, Pedro Grasses nota que "la guerra destruyó todo vestigio de estos testimonios que hoy serían invalorables para conocer las creaciones literarias de la generación de la independencia" (Grasses 1979: 71).

6 Hor. Sat. VI 2.

7 Cardozo notará la recurrencia de este motivo en otras poesías posteriores, ya de su época londinense, como en la Silva a la agricultura de la Zona Tórrida, ya de su época chilena, como en Al Bío-Bío.

8 Bello (1981: tomo I, 7). En adelante, todas las citas de obras de Andrés Bello están tomadas de esta edición. 
Lo mismo diremos de su obra como traductor, como la que hace de la oda I 14, también de Horacio, O navis, referent:

¿Qué nuevas esperanzas
al mar te llevan? Torna,
torna, atrevida nave,
a la nativa costa.
..
Presto erizando cerros
vendrá a batir las rocas,
y náufragas reliquias
hará a Neptuno alfombra...9

Andrés Bello tradujo a algunos de los más importantes clásicos de la poesía latina. Muchas de estas traducciones, la mayor parte extraviadas a causa de la guerra de independencia, le ganaron fama y notoriedad, especialmente en su primera etapa caraqueña. Entre las más importantes traducciones que se conservan se cuentan el comienzo de la Sátira 10 del libro I de Horacio, Fuese Lucilio enhorabuena (Lucili, quam sis mendosus...), la Oda II 16, Pide la dulce paz del alma al cielo (Otium divos rogat in patenti...) y la Oda I 14 A la nave (O navis referent...), que le valió ser incluido en la selección de las mejores traducciones de Horacio al español hecha por M. Menéndez Pelayo. De Plauto tradujo el prólogo y los tres primeros actos del Rudens o el cable del navio; de Tibulo los primeros 24 versos de la Elegía I, Atesore el avaro... (Divitias alius fulvo sibi congerat auro...) y de Virgilio es célebre su imitación de la Égloga II, Tirsis, habitador del Tajo umbrio... (Formosum pastor Corydon ardebat Alexim...). Algo similar diremos de sus imitaciones, como en aquella Égloga, confesamente Imitación de Virgilio, como reza el título mismo, ciertamente de la Egloga II del poeta romano:

Tirsis, habitador del Tajo umbrío, con el más vivo fuego a Clori amaba;

a Clori, que, con rústico desvío, las tiernas ansias del pastor pagaba.

La verde margen del ameno río, tal vez buscando alivio, visitaba; y a la distante causa de sus males, desesperado enviaba quejas tales:

"No huye tanto, pastora, el corderillo del tigre atroz, como de mí te alejas, ni teme tanto al buitre el pajarillo, ni tanto al voraz lobo las ovejas ..." ${ }^{\prime 10}$

\footnotetext{
Bello (1981: tomo I, 36).

10 Bello (1981: tomo I, 28).
} 
Ya para entonces Bello había aprendido de forma autodidacta inglés y francés, lo que quizás le valió el ser escogido para acompañar a Humboldt y Bonpland en enero de 1800, en su célebre excursión al cerro La Silla de Caracas, así como a otros lugares de la campiña caraqueña. Iván Jaksic (2007: 46) en su Andrés Bello. La pasión por el orden nos dice: "Para el joven caraqueño de dieciocho años, el encuentro con Humboldt fue una verdadera revelación intelectual, ya que tuvo la oportunidad de observar directamente el trabajo de dos experimentados naturalistas con sus instrumentos científicos". Sin duda se trató de una relación muy breve pero intensa, que dejó en el caraqueño una huella imborrable, como luego veremos.

Así pues, un jovencísimo Andrés Bello gozaba ya de indiscutible prestigio entre las élites de la pequeña capital colonial. Sus traducciones y sus poesías le habían dado fama y reconocimiento, por lo que frecuentemente era requerido como profesor particular entre los jóvenes aristócratas. De hecho en 1798 fue maestro de Simón Bolívar por un breve período. El futuro Libertador tenía entonces catorce años y Bello dieciséis.

Durante la primera década del s. XIX, Bello es sin duda uno de los intelectuales más influyentes de Caracas. En 1802 obtiene el cargo de Oficial Segundo de Secretaría del gobierno de la Capitanía General. Ese mismo año traduce la tragedia Zulima de Voltaire, lo que le gana aún más notoriedad. En 1808 es el primer criollo en ser nombrado Oficial de Guerra de la Capitanía General, cargo que no llega a ocupar. A la muy tardía llegada de la imprenta a Venezuela, en octubre de ese año, Bello se convierte en el candidato ideal para dirigir el primer periódico de la ciudad, la $\mathrm{Ga}$ zeta de Caracas. Como su redactor, será el autor del primer libro impreso del país: el Calendario Manual y Guía Universal de Forasteros en Venezuela para el año de 1810 (Grasses 1978: 34-37).

\section{Leer un lugar}

Los sucesos del 19 de abril de 1810, cuando el cabildo de Caracas destituyó al gobernador capitán Vicente de Emparan dando inicio a la independencia de Venezuela, supondrán un cambio radical en la vida del joven intelectual y hasta entonces exitoso funcionario colonial. Bello había participado en la conjura, si bien el grado de su implicación todavía se discute. La Junta Suprema de Caracas lo nombra Oficial Primero de la Secretaría de Relaciones Exteriores. El 10 de junio de 1810 Bello zarpa a bordo de la corbeta Wellington con destino a Portmuth junto con dos funcionarios más, Simón Bolívar y Luís López Méndez. Se sabe que entonces ya lleva adelantado su Análisis ideológico de los tiempos de la conjugación castellana, que no será dado a las prensas hasta treinta años después en Santiago ${ }^{11}$. Su misión en Londres tiene por objeto lograr el apoyo británico para la causa de la independencia. Allí los espera Francisco de Miranda, conspirador y revolucionario venezolano que ha hecho carrera militar en Europa y se ha convertido en una especie de contacto imprescindible para otros republicanos y liberales españoles y americanos en Londres. Las razones políticas y estratégicas por las que fracasa la misión venezolana han sido suficientemente documentadas. Bolívar decide volver

11 “...me he determinado a sacar esta obrilla de la oscuridad en que hace más de treinta años la he tenido sepultada". Prólogo a la primera edición, Santiago 1841. Cf. Nava Contreras (2010: 57) y Pérez Hernández (2007: 176 ss). 
a Caracas, mientras que López y Bello se quedan en Londres intentando mantener activa una representación diplomática. Cuando Venezuela declare oficialmente su independencia el 5 de julio del año siguiente, López y Bello serán designados representantes oficiales del nuevo gobierno.

El contacto de Bello con Miranda, hombre de inmensa cultura cosmopolita en cuya casa londinense de Grafton Way, no lejos del Museo Británico, se aloja y a cuya formidable biblioteca tiene acceso, deja profunda huella en el recién llegado. En efecto, Miranda, que sabe latín, griego (Castillo Didier 2007) y lenguas modernas, tiene una biblioteca completísima, llena de escogidas ediciones de los clásicos y completada con gusto y saber de fino bibliófilo (Uslar Pietri 1966; García Bacca 1969). Bello tuvo libre acceso a esa biblioteca, en la que aprendió de forma autodidacta el griego antiguo, tan sólidamente que más tarde pudo desempeñarse como profesor privado, aliviando sus frecuentes penurias económicas ${ }^{12}$. Serían tiempos de establecer relaciones con intelectuales y revolucionarios en la capital británica: el ilustrado sevillano José María Blanco White; el mexicano Servando Teresa de Mier; James Mill, el economista escocés; Jeremy Bentham, filósofo y economista; los chilenos Francisco Antonio Pinto, futuro presidente de ese país, y Antonio José de Irisarri, entonces encargado de negocios de la legación diplomática.

Pero son sobre todo años de intensos estudios, primero en la biblioteca de Miranda y después en la British Library, donde se dedica con profundidad a la filología, la filosofía del lenguaje y la literatura universal, según se ve en las profusas notas dejadas en sus Cuadernos de Londres ${ }^{13}$. Se encuentra en esta biblioteca, desempeñándose como investigador gracias a un pequeño estipendio que recibe del gobierno inglés desde 1816, cuando, en 1819, Lord Elgin presenta en el Museo Británico los mármoles del Partenón recién traídos de Atenas. Paralelamente, Bello desarrolla una importante labor como escritor, periodista y poeta. Dirige y redacta buena parte de las revistas El censor americano (1820), la Biblioteca americana (1823) y dirige El repertorio americano (1826). Estas publicaciones están llenas de artículos acerca de la cultura, la geografía e informaciones sobre los formidables recursos naturales del Nuevo Mundo, la mayoría firmados por el propio Bello. Muchos de estos artículos rememoran la profunda huella humboldtiana ${ }^{14}$. Consta también que Bello, entre sus actividades diplomáticas, redactó en 1820 una carta dirigida al papa Pío VII, en la que le informa de la penosa situación de la Iglesia a causa de la guerra y plantea la necesidad de un concordato entre la Santa Sede y la naciente república de Colombia. Los méritos estilísticos de la carta, redactada íntegramente en latín, han sido suficientemente resaltados ${ }^{15}$.

12 Cf. Castillo Didier (1996). Acerca de las gramáticas y métodos utilizados por Bello en su aprendizaje de las lenguas clásicas, $c f$. igualmente Velleman (1995: 62). Acerca de las clases de griego impartidas por Bello en Londres, en una carta dirigida a Pedro Gual, fechada el 14 de agosto de 1822, el caraqueño cuenta que "hasta el año de 1822, me ocupé llevando la correspondencia de una casa de comercio, y dando lecciones de español, latín y griego". Cf. Bello (1981: tomo XXV, 133). Acerca del dominio de la lengua griega por parte de Andrés Bello, $c f$. Espinoza Polit, "Bello helenista", en el prólogo a la Gramática latina (1981: tomo VIII, xcii-xcix).

13 Santiago de Chile 2017.

14 Estos artículos se encuentran reunidos en los tomos XXIII, "Historia y geografía", y XXIV, "Cosmografía y otros escritos", de sus Obras Completas (1981).

15 Dice Aurelio Espinoza Pólit que "la carta de 1820 a Pío VII es un documento de excepcional importancia en la Historia eclesiástica de América como primer conato de recurso a la Santa Sede de los pueblos independizados". El texto fue descubierto por el P. Pedro Leturia en 1925, si bien solo años después se supo que su autor había sido Andrés Bello. Cf. Espinoza Polit (Bello, 1981: tomo VIII, lxxvi). 
De estos años son también sus más célebres poemas, Alocución a la poesía (1823) y Silva a la agricultura de la Zona Tórrida (1826), cuya impecable factura y original propuesta estética les ganarán un importante lugar en la poesía hispanoamericana. Ambos poemas constituyen un ejemplo, el primero consciente para las letras americanas, de fecunda simbiosis entre el motivo grecolatino y la fértil naturaleza americana, hasta entonces desconocida para la poesía. Así en la Alocución a la poesía:

\author{
Divina poesía, \\ tú de la soledad habitadora \\ a consultar tus cantos enseñada \\ con el silencio de la selva umbría, \\ tú a quien la verde gruta fue morada, \\ y el eco de los montes compañía; \\ tiempo es que dejes ya la culta Europa, \\ que tu nativa rustiquez desama, \\ y dirijas el vuelo a donde te abre \\ el mundo de Colón su grande escena.
}

Tiempo vendrá cuando de ti inspirado algún Marón americano, ¡oh diosa! también las mieses, los rebaños cante, el rico suelo al hombre avasallado, y las dádivas mil con que la zona de Febo amada al labrador corona; donde cándida miel llevan las cañas, y animado carmín la tuna cría, donde tremola el algodón su nieve, y el ananás sazona su ambrosía; de sus racimos la variada copia rinde el palmar, de azucarados globos el zapotillo, su manteca ofrece la verde palta, da el añil su tinta, bajo su dulce carga desfallece el banano, el café el aroma acendra de sus albos jazmines, y el cacao cuaja en urnas de púrpura su almendra ${ }^{16}$.

No cabe duda de que la sólida formación adquirida por Bello en Londres será definitiva de la impresionante obra y actividad creativa desarrollada cuando vuelva a América y se radique, ya definitivamente, en Santiago de Chile. Para estos años, el caraqueño exhibe una particular poética que luce consolidada y que, para algunos, ha creado conscientemente (Cardozo 1981: 16); pero también una robusta formación filosófica que le permitirá llevar a cabo una ingente obra jurídica y política (Scocozza 1989, y Ardao 1986) ${ }^{17}$.

16 Bello (1981: tomo I, 43, 48; vv. 1-10, 189-206).

17 Que Bello superó su primera formación filosófica caraqueña y pudo tener contacto en Londres con las últimas corrientes de la filosofía europea lo prueba la frase mordaz con que se refiere a su vieja alma mater: "¿Y qué es de nuestra anciana y venerable nodriza? ¿Ha desechado ya enteramente el tontillo de la doctrina aristotélica- 


\section{Leer una obra}

Si la etapa londinense supuso para Bello un período crucial en la consolidación de su formación como intelectual y como humanista, la etapa final de su vida en Santiago significó la oportunidad de poner todos sus conocimientos en práctica, con el fin de ayudar en la construcción de una de las jóvenes repúblicas hispanoamericanas. En efecto, Andrés Bello ocupó puestos de responsabilidad prácticamente desde su llegada a la capital chilena. Fue académico del célebre Instituto Nacional y fundador y rector del Colegio de Santiago. Tuvo destacada participación en la llamada Sociedad Literaria y fue el principal impulsor y fundador de la Universidad de Chile, cuyos estatutos redactó y de la que fue rector desde su fundación en 1842 hasta su muerte. Colaboró en la redacción del influyente periódico El Araucano desde 1830 hasta 1853. Entre 1840 y 1855 fue el redactor del Código Civil chileno (1981: tomos XIV, XV y XVI), considerado como una referencia de la legislación civil hispanoamericana, y entre 1837 y 1864 se desempeñó como senador por la ciudad de Santiago. Su prestigio como autor de derecho internacional le valió el ser elegido como árbitro de diferendos internacionales, como el de Estados Unidos y Ecuador en 1864 y el de Colombia y Perú al año siguiente. En 1851 fue nombrado miembro honorario de la Real Academia Española. Murió el 15 de octubre de 1865 .

Fue durante esta etapa chilena cuando Bello publicó la mayor parte de su vasta obra filológica, lingüística y jurídica. Entre estos estudios destacan una Gramática de la lengua latina $(1846)^{18}$, unos Principios de derecho de gentes $(1832)^{19} \mathrm{y}$ una Historia de la literatura antigua $(1850)^{20}$, así como el ya mencionado Código Civil de Chile (1856). Sin embargo, la cumbre de tan vasta obra será sin duda la Gramática de la lengua castellana destinada al uso de los hispanoamericanos $(1847)^{21}$. De ella es necesario que citemos las apreciaciones que hace Ivan Jaksic (2007: 266-267):

Como ya había discutido en algunos escritos en Inglaterra y en Chile, su preocupación principal era que la gramática más importante, la de la Real Academia Española, estaba basada en el latín, no solo para la ortografía sino también para la conjugación de los verbos y la declinación de los sustantivos [...] Cuando publicó su Gramática de la lengua castellana en 1847, ya llevaba un cuarto de siglo acumulando materiales, y afinando los conceptos que hicieron de su obra un éxito nacional e internacional. Una parte importante de este éxito se debió no tanto a su erudición, que era abundante, sino a la peculiar respuesta que daba a las preocu-

tomista, y consentido vestirse a la moderna? No dudo que sí" (Carta a Pedro Gual, Londres, 6 de enero de 1825. Cf. 1981: tomo XXV, 142).

18 La Gramática latina (1981, tomo VIII) fue compuesta por el hijo de Andrés Bello, Francisco Bello Boyle, si bien debe ser atribuida en justicia a su padre, no solo por confesión del mismo Francisco, en que reconoce el haberse valido incesantemente de los conocimientos de su padre, sino porque, en efecto, en la primera edición de 1838 que reposa en la Biblioteca Nacional de Chile, "apenas hay página que no lleve numerosas correcciones de mano de don Andrés Bello" (Espinoza Polit 1981: XI).

19 Publicados como Principios de Derecho Internacional, (1981: tomo X).

20 La segunda y tercera parte de su Compendio de historia de la literatura están dedicadas a la Literatura antigua de Grecia y la Literatura latina (1981: tomo IX, 3-196).

21 Tomo IV. 
paciones políticas, propias de la independencia, acerca de la identidad nacional y supranacional en materia de lenguaje ${ }^{22}$.

A estos títulos mayores habrá que agregar otros estudios menores de no menos profundidad filológica. Entre ellos, vale la pena mencionar los opúsculos de métrica Del ritmo y del metro de los antiguos y Del ritmo latino-bárbaro, así como Sobre el origen de las varias especies de metros usados en la poesía moderna (1981: tomo VIII, 149-168) ${ }^{23}$. En ortología destaca el trabajo Qué diferencia hay entre las lenguas griega y latina por una parte, y las lenguas romances por otra en cuanto a los acentos y cuantidades de las sílabas; y qué plan deba abrazar un tratado de prosodia para la lengua castellana (1985: 491) 24. En cuanto a la crítica literaria, vale la pena destacar su valoración de los Estudios sobre Virgilio de P. F. Tissot (París 1825) publicada en El Repertorio Americano en 1826 (1981: tomo IX, 215224) 25 ; así como la severa crítica que hace a la versión de las Poesías de Horacio hecha por Javier de Burgos en $1820^{26}$, igualmente publicada en El Repertorio Americano en 1827 (1981: tomo IX, 251-288) ${ }^{27}$. Bello fue también en 1830 responsable de la edición chilena del libro de Charles François Lhomond, Epitome historiae sacrae, entonces popular texto de estudio eclesiástico, y en 1847 redactó las notas a una edición latina de las Tristias de Ovidio ${ }^{28}$. Finalmente, hay que mencionar también los artículos de prensa "Sobre el estudio de la lengua latina" y "Latín y Derecho Romano", aparecidos en El Araucano en 1831 y 1834 respectivamente, donde hace una vigorosa defensa de los estudios clásicos. Se conserva asimismo una edición de las tragedias de Esquilo, lamentablemente imposible de identificar por haber perdido las primeras páginas, que reposa en el Museo Bibliográfico de Santiago de Chile. La edición íntegra en griego, sin traducción ni notas, muestra una gran cantidad de notas en latín de puño y letra de Andrés Bello (Espinoza Polit 1981: tomo VIII, XCII-XCIX).

\section{Conclusiones}

La edición más completa de las Obras completas de Andrés Bello tiene veintiséis tomos y fue editada por la Fundación La Casa de Bello en Caracas, entre 1981 y $1984^{29}$. Allí se contiene toda la impresionante obra del caraqueño, salvo los

22 Igualmente, R. Caldera (2015: 153) afirma que “Don Andrés Bello fue partidario del estudio del latín, pero defendió la diferencia completa entre nuestra Gramática y la Gramática de la lengua madre. Tal fue su empeño básico. Que lo consiguió plenamente, lo acredita Menéndez y Pelayo: 'a él se debe, más que a otro alguno, el haber emancipado nuestra disciplina gramatical de la servidumbre en que vivía respecto de la latina, que torpemente se quería adaptar a un organismo tan diverso como el de las lenguas romances","

23 Miguel Luís Amunátegui localizó este trabajo entre los papeles de Bello y lo hizo publicar póstumamente.

24 Publicado por primera vez en la Biblioteca Americana, II, Londres 1823: 24-40.

25 Publicado por primera vez en El Repertorio Americano, Londres, octubre de 1826: 19-26.

26 Acerca de la traducción, $c f$. Elías Muñoz (2016).

27 Publicado por primera vez en El Repertorio Americano, Londres, abril de 1827: 93-111.

28 P. Ovidii Nasonis. Tristium Libri V, Notis hispanici illustratis. Jacobopoli. Ex typographo Chilensi. MDCCCXLVII.

29 Existen otras ediciones previas, como la primera chilena en quince tomos (Santiago 1881-1893); una española, parcial, en siete tomos (Madrid 1882-1905); una segunda chilena, incompleta, en nueve tomos (Santiago 19301935), y una primera venezolana en veinticuatro tomos (Caracas 1952-1981). La última edición caraqueña es facsimilar de la de 1952, si bien incluye la obra epistolar de Bello. 
apuntes que tomó en la British Library durante casi diez años, de 1814 a 1823 , cuya publicación hace dos años en Santiago de Chile marca hasta ahora el fin del Andrés Bello inédito.

Sin duda la valoración de una obra tan amplia plantea formidables problemas, especialmente cuando la ponemos en relación con la tradición clásica. Sin embargo no derivan estos problemas de la extensión de la obra, como sí de su variedad y de su particular circunstancia histórica, geográfica y cultural. Esto porque el de Bello es un tiempo de transición, un período crepuscular en el que el viejo orden colonial declina y da paso al surgimiento de un nuevo contexto republicano en la América hispana, un orden postcolonial. Sin embargo esta transición no será solamente política. Paralelamente, importantes mudanzas se están verificando en las artes, el pensamiento y las ciencias en Europa. Dice al respecto Carlos Ossandon Buljevic (2013: 43): "No es ciertamente novedoso afirmar que Andrés Bello se sitúa en una particular coyuntura histórica, en una intersección de mundos, en un período de transición cultural y política que va a tener importantes consecuencias para América Latina" ${ }^{30}$. En el surgimiento de este nuevo pensamiento Bello sabe vislumbrar un lugar para las nuevas repúblicas americanas, un nuevo espacio para una cultura y una estética republicanas. En este sentido, todo intento de clasificación bajo códigos ortodoxos resulta inefectivo. Dice así Miguel Ángel Campos en su ensayo "Andrés Bello: el mundo que lo produjo" (2017: 14):

Romántico o neoclásico, la identidad no le hace justicia, resulta una discusión inocua, en un observador de la novedad cuyo escenario de acción no es la mera coyuntura de la política, tampoco la burocracia del funcionariado de la república y sus privilegios. Monárquico o republicano, conservador o liberal, en aquellas doctrinas no ve principios concluyentes, verá antes usos que deberán comprobarse en la utilidad pública. Multitud de pasajes de su obra escrita nos muestran su determinación de conciliador orientado hacia el ajuste de lo real, ante lo nuevo y sin precedentes el legislador, asesor, maestro, interroga lo dado puesta la mirada en una síntesis de experiencia e imaginación: he ahí su heterodoxia.

Con estas palabras damos por saldada una antigua querella por clasificar la poesía de Bello ${ }^{31}$. Dice también en ese sentido Antonio Cussen (1995: 15):

Es su destiempo, este conflicto de una voz clásica con un mundo que subvierte inexorablemente todos los principales baluartes de la cultura clásica, lo que constituye el atractivo peculiar de su poesía.

Tenemos que pensar, pues, que este conflicto se traslada más allá de los espacios de lo poético. Bello ensaya un nuevo lenguaje integrador y conciliador, en el que la formación clásica es el principio rector. De nuevo se hacen útiles las apreciaciones de Campos (2017: 13): "Si algo tienen en común las tres estancias de Bello, y en

30 Como dice el autor, no se trata solamente de la independencia de la América hispana, son también la de las colonias inglesas o la revolución industrial británica.

31 Acerca de la vieja polémica acerca de su la poesía de Andrés Bello es neoclásica o romántica, $c f$. Rodríguez Monegal (1979) y Cardozo (1981: 16). El asunto también es ampliamente tratado en Crema (1987: 13-217). 
escenarios no sólo distintos sino opuestos, es su capacidad de elaborar y fundar sometiendo la tradición a su propio canon, integrando los recursos locales a una eficacia máxima de sus instrumentos de relacionamiento". Estos recursos e instrumentos exceden, repetimos, la poesía.

Si, como asegura Francisco García Jurado (2016: 229), es posible relacionar los estudios de tradición clásica con los estudios postcoloniales, y en ese sentido, siguiendo a Tarcisio Herrera, en la América colonial "la tradición clásica se identifica con el humanismo propiamente dicho"32, el caso de Andrés Bello plantea una serie de retos que sin duda ayudarán a enriquecer esta valoración. Son ellos:

1. Al abarcar su obra y espacio vital un arco de transición que va del tardío escolasticismo colonial, pasando por la Ilustración, hasta el franco romanticismo, no podemos decir que el humanismo clásico en Andrés Bello se corresponda con unos cánones estéticos específicos, sino que, más bien, los trasciende aunque en continuo diálogo con ellos.

2. Su estética se basa en un esfuerzo conciliador entre el referente grecolatino y la avasallante realidad del entorno americano. En este sentido, el referente, adaptado, toma nuevos matices y alcanza nuevas formas en su dimensión universal. El resultado será, inevitablemente, una nueva estética, inédita, original y fundadora.

3. El intento abarcador y universalista no se limita únicamente al referente estético. Antes bien, Bello concibe al humanismo clásico desde una pedagogía republicana, y por ende desde una perspectiva eminentemente pragmática. Su proyecto es integral, a cuyo servicio pone toda su erudición. Abarca desde la filología, la métrica o la crítica literaria hasta los estudios jurídicos, la diplomacia, el derecho internacional, el periodismo o la divulgación científica. En este sentido, no podemos acompañar algunas afirmaciones que pretenden que las nuevas repúblicas hispanoamericanas hayan sido fundadas con un espíritu anticlásico, confundiendo antihispanismo con anticlasicismo. Por otra parte, es útil tomar en cuenta los factores biográficos del autor, más allá de la historia cultural.

4. Finalmente, el cultivo del humanismo clásico no necesariamente tiene que tener por objeto su propia afirmación, sino que, por el contrario, puede servir para trascenderlo y superarlo en aquellas disciplinas en que fuera necesario. Son los clásicos tras los clásicos. Muchas veces el humanismo clásico subyace y da forma a obras donde aparentemente no hay rastro de él. Es el caso de la Gramática de la lengua castellana, donde Bello consigue superar los problemas de la gramática canónica, ocasionados por el intento de forzar la lengua viva al esquema de la gramática latina tradicional. En este sentido, también destaca la función del humanismo clásico al servicio de un proyecto que ambiciosamente une gramática con política.

32 "La llegada, en especial, de la lengua latina a América y el desarrollo del humanismo grecolatino en este nuevo contexto cultural ha sido y viene siendo una vigorosa rama de estudios que ha favorecido después el desarrollo de monografías específicas sobre el humanismo y la tradición clásica desde el ámbito de las diferentes naciones hispanoamericanas. En algunas monografías, como en el caso de la de Tarcisio Herrera, la tradición clásica se identifica con el humanismo propiamente dicho". La cita es de Herrera Zapién (2000). 


\section{Bibliografía}

Ardao, Antonio (1986), Andrés Bello, filósofo, Caracas, Academia Nacional de la Historia.

Bello, Andrés (2017), Cuadernos de Londres. Genealogía de las ideas de Bello, Santiago de Chile, Editorial Universitaria.

Bello, Andrés (1981-1984), Obras completas, Caracas, Ediciones La Casa de Bello.

Bello, Andrés (1985), Obra literaria, selección y prólogo de Pedro Grasses, cronología de Oscar Sambrano Urdaneta, Caracas, Biblioteca Ayacucho.

Caldera, Rafael (2015), Andrés Bello, Caracas, Ediciones Cyngular (1º ed. 1935).

Campos, Miguel Ángel (2017), «Andrés Bello: el mundo que lo produjo», Presente y pasado 43: 11-27.

Cardozo, Lubio (1981), La poética de Andrés Bello y sus seguidores, Caracas, Academia Nacional de la Historia.

Castillo Didier, Miguel (2007), Grecia y Francisco de Miranda, Caracas, Monte Ávila Editores Latinoamericana.

Castillo Didier, Miguel (1996), Miranda y la senda de Bello, Caracas, Ediciones La Casa de Bello.

Crema, Edoardo (1987), Estudios sobre Andrés Bello, Caracas, Ediciones La Casa de Bello.

Cussen, Antonio (1995), Bello y Bolívar. Poesía y politica en la revolución hispanoamericana, traducción de Gustavo Díaz Solís, Caracas, Ediciones La Casa de Bello.

Elías Muñoz, Ismael (2016), «El horacianismo de Javier de Burgos en su contexto histórico, sociocultural y literario», Tesis doctoral, Madrid, Universidad Complutense de Madrid.

García Bacca, Juan David (1969), Los clásicos griegos de Miranda, Caracas, Universidad Central de Venezuela.

García Jurado, Francisco (2016), Teoría de la tradición clásica. Conceptos, historia y métodos, México, Universidad Autónoma Nacional de México.

Grasses, Pedro (1978), Algunos temas de Bello, Caracas, Monte Ávila Editores.

Henríquez Ureña, Pedro (1994), Historia de la cultura en la América Hispánica, México, Fondo de Cultura Económica.

Herrera Zapién, Tarcisio (2000), Historia del humanismo mexicano, México, Porrúa. Jaksic, Iván (2007), Andrés Bello. La pasión por el orden, Caracas, Bid \& Co. Editor.

Leal, Ildefonso (1981), Historia de la UCV, Caracas, Universidad Central de Venezuela.

Nava Contreras, Mariano (2010), Envuelto en el manto de Iris, Mérida (Venezuela), Universidad de Los Andes.

Nava Contreras, Mariano (2016), «Ex Philosopho probatur. Apuntes para una historia del aristotelismo colonial venezolano», Praesentia. Revista Venezolana de Estudios Clásicos, número especial, Praesentia aristotelica. Lecturas venezolanas de Aristóteles: $82-132$.

Nava Contreras, Mariano (1997), «Los Cursus philosophici de Suárez y Urbina. El latín colonial en Venezuela y dos manuscritos filosóficos», $C F C$ (L) 12: 179-182.

Ossandón Buljevic, C. \& Ruiz Schneider, C. (coords.) (2013), Andrés Bello. Filosofía pública y política de la letra, Santiago de Chile, Fondo de Cultura Económica Chile.

Parra León, Caracciolo (1989), Filosofía universitaria venezolana, Caracas, Universidad Central de Venezuela. 
Pérez Hernández, Francisco Javier (2007), Del lado de los cautivos, Caracas, Bid \& Co. Editor.

Rodríguez Monegal, Emir (1979), El otro Andrés Bello, Caracas, Monte Ávila Editores.

Scocozza, Antonio (1989), Filosofía, politica y derecho en Andrés Bello, Caracas, Ediciones La Casa de Bello.

Tejera, María Josefina (1996), «La decadencia del latín como lengua del saber en Venezuela», Praesentia. Revista Venezolana de Estudios Clásicos 1: 359-379.

Uslar Pietri, Arturo (1966), Los libros de Miranda, Caracas, Ediciones del Cuatricentenario de Caracas.

Velleman, Barry (1995), Andrés Bello y sus libros, Caracas, Ediciones La Casa de Bello. 